\title{
Behavioral Characterization of $\kappa$ Opioid Receptor Agonist Spiradoline and Cannabinoid Receptor Agonist CP55940 Mixtures in Rats ${ }^{[}$
}

\author{
Vanessa Minervini, Sujata Dahal, and Charles P. France \\ Departments of Pharmacology (V.M., S.D., C.P.F.) and Psychiatry (C.P.F.), University of Texas Health Science Center at San \\ Antonio, San Antonio, Texas
}

Received June 3, 2016; accepted November 29, 2016

\begin{abstract}
Pain is a significant clinical problem, and there is a need for more effective treatments with reduced adverse effects that currently limit the use of $\mu$ opioid receptor agonists. Synthetic $\kappa$ opioid receptor agonists have no abuse liability and well-documented antinociceptive effects; however, adverse effects (diuresis, dysphoria) preclude their use in the clinic. Combining $\kappa$ opioids with nonopioid drugs (cannabinoid receptor agonists) allows for smaller doses of each drug to produce antinociception. This study tested whether a potentially useful effect of the $\kappa$ opioid receptor agonist 2-(3,4dichlorophenyl)-N-methyl-N-[(5R,7S,8S)-7-pyrrolidin-1-yl-1-oxaspiro[4.5]decan-8-yl] (spiradoline; antinociception) is selectively enhanced by the cannabinoid receptor agonist 2-[(1R,2R,5R)-5hydroxy-2-(3-hydroxypropyl) cyclohexyl]-5-(2-methyloctan-2-yl)phenol (CP55940). Cumulative dose-response functions were determined in eight male Sprague-Dawley rats for spiradoline (0.032-32.0 mg/kg, i.p.) and CP55940 (0.0032-1.0 mg/kg, i.p.) for
\end{abstract}

antinociception, hypothermia, food-maintained responding, and diuresis. Alone, each drug dose dependently increased tail withdrawal latencies from $50^{\circ} \mathrm{C}$ water, decreased body temperature by $\sim 4^{\circ} \mathrm{C}$, and eliminated food-maintained responding. Spiradoline, but not CP55940, significantly increased urine output at doses that eliminated responding. Smaller doses of spiradoline and CP55940 in mixtures (3:1, 1:1, and 1:3 spiradoline:CP55940) had effects comparable to those observed with larger doses of either drug administered alone: the interaction was additive for antinociception and additive or greater than additive for hypothermia and food-maintained responding. Collectively, these data fail to provide support for the use of these mixtures for treating acute pain; however, $\kappa$ opioid/cannabinoid mixtures might be useful for treating pain under other conditions (e.g., chronic pain), but only if the adverse effects of both drugs are not enhanced in mixtures.

\section{Introduction}

Pain is the most common reason people seek medical care (St Sauver et al., 2013); $\mu$ opioid receptor agonists remain the drugs of choice for treating moderate to severe pain despite welldocumented adverse effects (e.g., respiratory depression, abuse, overdose). Of all prescription medications, $\mu$ opioid receptor agonists are the most widely abused, and fatal overdoses have reached epidemic levels (Rosenblatt and Catlin, 2012; Volkow et al., 2014; http://www.cdc.gov/drugoverdose/index. $\mathrm{html}$ ). There is a need for more effective treatments that have fewer of the deleterious effects that currently limit the clinical use of opioids. Unlike $\mu$ opioid receptor agonists, synthetic

This work was supported by the National Institutes of Health National Institute on Drug Abuse [Grants K05DA017918 and T32DA031115] and the Welch Foundation [Grant AQ-0039].

The content expressed here is solely the responsibility of the authors and does not necessarily represent the views of the National Institutes of Health.

Portions of this manuscript were presented at the 2016 annual meetings Experimental Biology and American Society for Pharmacology and Experimental Therapeutics in San Diego, CA, and Behavior, Biology, and Chemistry: Translational Research in Addiction in San Antonio, TX. Minervini V and France CP, Behavioral characterization of spiradoline and CP55940 in rats: potential of drug mixtures for treating pain. EB2016 (poster). Sujata D Minervini V, and France CP, Additive effects of spiradoline and CP55940 in rats: potential of drug mixtures for treating pain. Behavior, Biology and Chemistry: Translational Research in Addiction 2016 (poster).

dx.doi.org/10.1124/jpet.116.235630.

S This article has supplemental material available at jpet.aspetjournals.org. $\kappa$ opioid receptor agonists are not likely to be abused because they are devoid of positive reinforcing effects (Woods and Winger, 1987; Chavkin, 2011; Tejeda et al., 2013; Lalanne et al., 2014). The antinociceptive effects of $\kappa$ opioid receptor agonists are comparable to those of $\mu$ opioid receptor agonists in various animal models of pain (Desmeules et al., 1993; Binder et al., 2001; Smith et al., 2008; Kivell and Prisinzano, 2010; Gerak and France, 2016); however, doses producing antinociception also produce conditioned place aversion and diuresis (Leander, 1983; Shippenberg and Herz, 1987; Zhang et al., 2005). Significant adverse effects of $\kappa$ opioids that preclude their use in the clinic include dysphoria, hallucinations, and diuresis (Pfeiffer et al., 1986; Peters et al., 1987; Walsh et al., 2001). However, the therapeutic potential of $\kappa$ opioids might be realized if smaller doses produced antinociception without adverse effects, thereby creating a favorable therapeutic window.

One strategy for possibly avoiding adverse effects is to combine $\kappa$ opioids with drugs that produce antinociception through nonopioid mechanisms (e.g., cannabinoid receptor agonists). Mixtures of smaller doses of a $\kappa$ opioid and a cannabinoid have antinociceptive effects that are equivalent to the effects of larger doses of either drug given alone, and this interaction is additive (Maguire and France, 2016). The use of smaller doses to achieve the desired (therapeutic) effect might also reduce the likelihood of adverse effects; for example, cannabinoids do not enhance the discriminative stimulus or reinforcing effects of $\mu$ opioid receptor 
agonists (Maguire et al., 2013). If adverse effects are not apparent at smaller doses, then $\kappa$ opioid/cannabinoid mixtures could be useful for treating pain and might be preferred to $\mu$ opioid receptor agonists.

$\kappa$ opioid receptors are thought to mediate, in part, antinociceptive, but not other (e.g., cataplexy) effects of cannabinoid receptor agonists (Smith et al., 1994) through spinal mechanisms and the release of endogenous opioids such as dynorphin B (Pugh et al., 1996, 1997). Furthermore, although $\kappa$ opioids and cannabinoids can have shared adverse effects, those shared effects can be mediated by different mechanisms, thereby allowing for smaller doses of each drug (in mixtures) to produce antinociception, compared with larger doses of either drug alone, and potentially avoiding adverse effects. This study characterized the effects of the $\kappa$ opioid receptor agonist 2-(3,4-dichlorophenyl)-N-methyl-N-[(5R,7S,8S)-7-pyrrolidin-1yl-1-oxaspiro[4.5]decan-8-yl] (spiradoline) and the nonselective CB1/CB2 cannabinoid receptor agonist 2-[(1R,2R,5R)-5hydroxy-2-(3-hydroxypropyl) cyclohexyl]-5-(2-methyloctan2-yl)phenol (CP55940), alone and in mixtures, to test the hypothesis that the potency of spiradoline/CP55940 mixtures to produce antinociception is greater than the potency to produce adverse effects. A warm water tail withdrawal procedure was used to measure antinociceptive effects. Hypothermia, diuresis, and rate-decreasing effects (food-maintained responding) served as indices of adverse effects. Hypothermia and diuresis have been reported for both cannabinoids and $\kappa$ opioids (Dykstra et al., 1987; Adler and Geller, 1993; McGregor et al., 1996; Wadenberg, 2003; Rawls and Benamar, 2011; Paronis et al., 2012, 2013; Chopda et al., 2013). Foodmaintained responding was used to assess behavioral suppression. The nature of the interaction between spiradoline and CP55940 was examined quantitatively using dose-additivity analyses (Tallarida, 2006, 2011).

\section{Materials and Methods}

\section{Subjects}

Eight male Sprague-Dawley rats (Harlan Sprague-Dawley, Indianapolis, IN) weighed 230-250 g upon arrival and were individually housed in $45 \times 24 \times 20$-cm plastic cages with rodent bedding (Harlan Teklad, Madison WI). Rats had free access to standard rodent chow (Harlan Teklad) and water for 2 weeks while they were habituated to handling. Once experiments began, rats were fed 5-15 g daily, allowing them to grow such that they weighted approximately $85 \%$ of the body weight of free-feeding rats. Thereafter, body weights were maintained at $350 \pm 5 \mathrm{~g}$ by daily food rations provided after sessions. Water was continuously available outside of experimental sessions. A 14:10 light:dark cycle was in effect (lights on at 0630 hours) with sessions conducted during the light period (starting between 1100 and 1200 hours and lasting 3 hours). The same rats were used in all assays, with drug tests separated by at least 1 week. Operant (food) sessions were conducted 6-7 days per week, excluding days on which antinociception tests occurred (for detailed description of order of drug testing across assays, see Drugs section below). The experimental protocol was approved by the Institutional Animal Care and Use Committee at the University of Texas Health Science Center at San Antonio and in accordance with guidelines set forth by the Guide for the Care and Use of Laboratory Animals (2011).

\section{Apparatus and Procedure}

Warm Water Tail Withdrawal and Body Temperature. Warm water tail withdrawal was used to measure antinociceptive effects, and body temperature was assessed during the same sessions.
Water baths (EW-14576-00; Cole-Parmer, Vernon Hills, IL) were maintained at $40^{\circ} \mathrm{C}, 50^{\circ} \mathrm{C}$, and $55^{\circ} \mathrm{C}$. Sessions comprised six 30 -minute cycles, with an injection given at the start of each cycle. After each injection, the rat was returned to its home cage for 28 minutes. Next, the rat was positioned on the palm of the experimenter's hand, and $5 \mathrm{~cm}$ of the tail was lowered into a water bath. Three water temperatures were tested in a randomized order and separated by approximately 20 seconds. Latency (seconds) to completely remove the tail from the water was recorded by the experimenter using a stopwatch. To avoid any adverse effects, the maximum possible latency was 20 seconds. Body temperature was recorded at the end of each cycle with a rectal thermometer (PhysiTemp Instruments, Clifton, NJ), and the next injection was given before returning the rat to its home cage. Vehicle injections were given in the first cycle, and cumulative doses of drug were given in the remaining five cycles, with the stipulation that latencies in the first cycle were not more than 5 seconds for $50^{\circ} \mathrm{C}$ and $55^{\circ} \mathrm{C}$ water and were at least 15 seconds for $40^{\circ} \mathrm{C}$ water. When the maximum (20-second) latency was observed for $50^{\circ} \mathrm{C}$ water during a cycle, tail withdrawal latencies were not assessed in subsequent cycles; however, cumulative dosing continued for the remaining cycles to assess drug effects on body temperature and to standardize drug exposure among subjects.

Food-Maintained Responding and Urine Output. Sessions were conducted in commercially available operant conditioning chambers $(31 \times 24 \times 21 \mathrm{~cm}$; ENV-008CT; Med Associates, St. Albans, VT) enclosed in ventilated, sound-attenuating cubicles (ENV-022M; Med Associates). The side panels of the chamber were Plexiglas, and the rear and front panels were aluminum. The front panel was equipped with two response levers horizontally aligned $11.5 \mathrm{~cm}$ apart. Above each lever was a 2.5 -cm-diameter translucent disk that could be illuminated white with a $100 \mathrm{~mA}$ light (lever lights). A feeder dispensed 45-mg food pellets (PJAI-0045; Noyes Precision Pellets, Research Diets, New Brunswick, $\mathrm{NJ})$ to a $5 \times 5$-cm food aperture centrally located between the two levers. The rear panel was equipped with a $100 \mathrm{~mA}$ house light centered $2 \mathrm{~cm}$ from the top of the chamber. The chamber had a steel rod floor, below which a drop pan with bedding collected feces and urine. MED-PC IV software and a PC-compatible interface (Med Associates) controlled stimulus events and recorded data.

As for antinociception studies, operant sessions consisted of six 30-minute cycles. After a 25-minute timeout, when the chamber was dark and responses to either lever were recorded but had no programmed consequence, the house light and left lever light were illuminated and completion of 10 consecutive responses on the left lever (fixed-ratio 10 schedule) resulted in the delivery of a food pellet (signaled with a 0.1second flash of the house light). When 10 pellets were delivered before 5 minutes elapsed, the house light and the lever light were extinguished for the remainder of the cycle. At the end of each session, feces were removed from the drop pan and the pan was weighed; the difference in the weight of the pan before and after the session provided a measure of urine output.

Drug tests occurred after three consecutive nondrug sessions in which overall response rates were within $20 \%$ of the mean. For drug tests, vehicle was injected in the first cycle and cumulative doses of drug in the remaining five cycles. Additionally, there were four sessions in which saline was administered in all cycles to control for handling and injecting; the criteria for saline tests were the same as for drug tests.

\section{Drugs}

Spiradoline (Upjohn, Kalamazoo, MI) was dissolved in a sterile 0.9\% saline solution; CP55940 (Sigma-Aldrich, St. Louis, MO) and spiradoline/CP55940 mixtures were dissolved in 1:1:18 solution of ethanol, emulphor, and saline, respectively. Injections were given i.p. in a volume of $1 \mathrm{ml} / \mathrm{kg}$ body weight. For all procedures, cumulative doses were administered with 30-minute interinjection intervals, and all drug tests (sessions) were separated by at least 1 week. Spiradoline and CP55940 dose-response curves were determined in an alternating order; rats were randomly assigned to initially receive either spiradoline or CP55940. The first drug test was conducted for food-maintained responding and urine 
output and the second for antinociception and body temperature; this order of testing alternated until dose-response curves for spiradoline and CP55940, each administered alone, were determined twice for each rat. The mean $\mathrm{ED}_{50}$ values for antinociception $\left(50^{\circ} \mathrm{C}\right.$ water) and response rates for food were used to determine the doses for spiradoline/CP55940 mixtures in ratios of 3:1, 1:1, and 1:3 (see Table 1, also Fig. 1B). Doseresponse curves for drug mixtures were singly determined for antinociception and body temperature [3:1, 1:3, and 1:1 spiradoline:CP55940 (order randomly selected but consistent across rats)] and then for foodmaintained responding and urine output (1:1, 1:3, 3:1 spiradoline: CP55940).

\section{Data Analyses}

Tail withdrawal latency was expressed as a percentage of the maximum possible effect according to the following formula: (test latency - control latency $/ 20-$ control latency) $\times 100$, where control latency corresponds to the effect of vehicle in the first cycle. Only data from $50^{\circ} \mathrm{C}$ water are shown because latencies were nearly exclusively 20 seconds for $40^{\circ} \mathrm{C}$ water and less than 5 seconds for $55^{\circ} \mathrm{C}$ water. Rectal body temperature was expressed as a percentage of the maximum effect according to the following formula: (test body temperature - control body temperature/33.5 - control body temperature) $\times 100$. A maximum of $33.5^{\circ} \mathrm{C}$ was selected because the lowest body temperatures observed for any individual rat were $33.3^{\circ} \mathrm{C}$ and $33.4^{\circ} \mathrm{C}$, respectively, for spiradoline and CP55940 given alone. Response rates for food were expressed as a percentage of the control response rate according to the following formula: (test response rate/control response rate) $\times 100$. Urine output was expressed as an absolute change (g) from control. The mean from the three preceding sessions served as the control for response rate as well as urine output.

For each rat, data were averaged across two determinations for each drug test, and then a linear regression was fit to those dose-response curves. A linear regression was fit to dose-response curves encompassing doses that ranged from ineffective to effective, using the largest dose that produced not more than $20 \%$ effect and the smallest dose that produced at least $80 \%$ effect to define the linear portion of the curve. No more than one dose producing less than $20 \%$ effect was included, and no more than one dose producing greater than $80 \%$ was included. $\mathrm{ED}_{50}$ values for each rat were determined, and those values were averaged across the group to provide the basis for the doses used in the mixtures. Dose-response data were not obtained for urine output because cumulative doses were administered in operant sessions and urine output was measured only at the end of each session. The interaction between spiradoline and CP55940 for antinociception, body temperature, and food-maintained

TABLE 1

Doses $(\mathrm{mg} / \mathrm{kg})$ of spiradoline and CP55940 in drug mixtures

\begin{tabular}{|c|c|c|c|c|c|c|}
\hline \multirow[b]{3}{*}{ Cycle } & \multicolumn{6}{|c|}{ Spiradoline:CP55940 (mg/kg) } \\
\hline & \multicolumn{2}{|c|}{$3: 1$} & \multicolumn{2}{|c|}{$1: 1$} & \multicolumn{2}{|c|}{$1: 3$} \\
\hline & Spiradoline & CP55940 & Spiradoline & CP55940 & Spiradoline & CP55940 \\
\hline \multicolumn{7}{|c|}{ Antinociception and body temperature } \\
\hline 1 & Vehicle & Vehicle & Vehicle & Vehicle & Vehicle & Vehicle \\
\hline 2 & 1.45 & 0.016 & 0.48 & 0.016 & 0.48 & 0.047 \\
\hline 3 & 2.90 & 0.031 & 0.97 & 0.031 & 0.97 & 0.094 \\
\hline 4 & 5.81 & 0.063 & 1.94 & 0.063 & 1.94 & 0.188 \\
\hline 5 & 11.61 & 0.125 & 3.87 & 0.125 & 3.87 & 0.375 \\
\hline 6 & 23.22 & 0.250 & $7.74^{a}$ & $0.250^{a}$ & 7.74 & 0.750 \\
\hline \multicolumn{7}{|c|}{ Response rate and urine output } \\
\hline 1 & Vehicle & Vehicle & Vehicle & Vehicle & Vehicle & Vehicle \\
\hline 2 & 0.21 & 0.008 & 0.07 & 0.008 & 0.07 & 0.024 \\
\hline 3 & 0.41 & 0.016 & 0.14 & 0.016 & 0.14 & 0.049 \\
\hline 4 & 0.83 & 0.033 & 0.28 & 0.033 & 0.28 & 0.098 \\
\hline 5 & 1.65 & 0.065 & 0.55 & 0.067 & 0.55 & 0.220 \\
\hline 6 & 3.30 & 0.130 & $1.10^{b}$ & $0.130^{b}$ & 1.10 & 0.390 \\
\hline
\end{tabular}

${ }^{a} \mathrm{ED}_{50}$ of drugs given alone for antinociceptive effects $\left(50^{\circ} \mathrm{C}\right.$ water $)$.

${ }^{b} \mathrm{ED}_{50}$ of drugs given alone for effects on food-maintained responding.

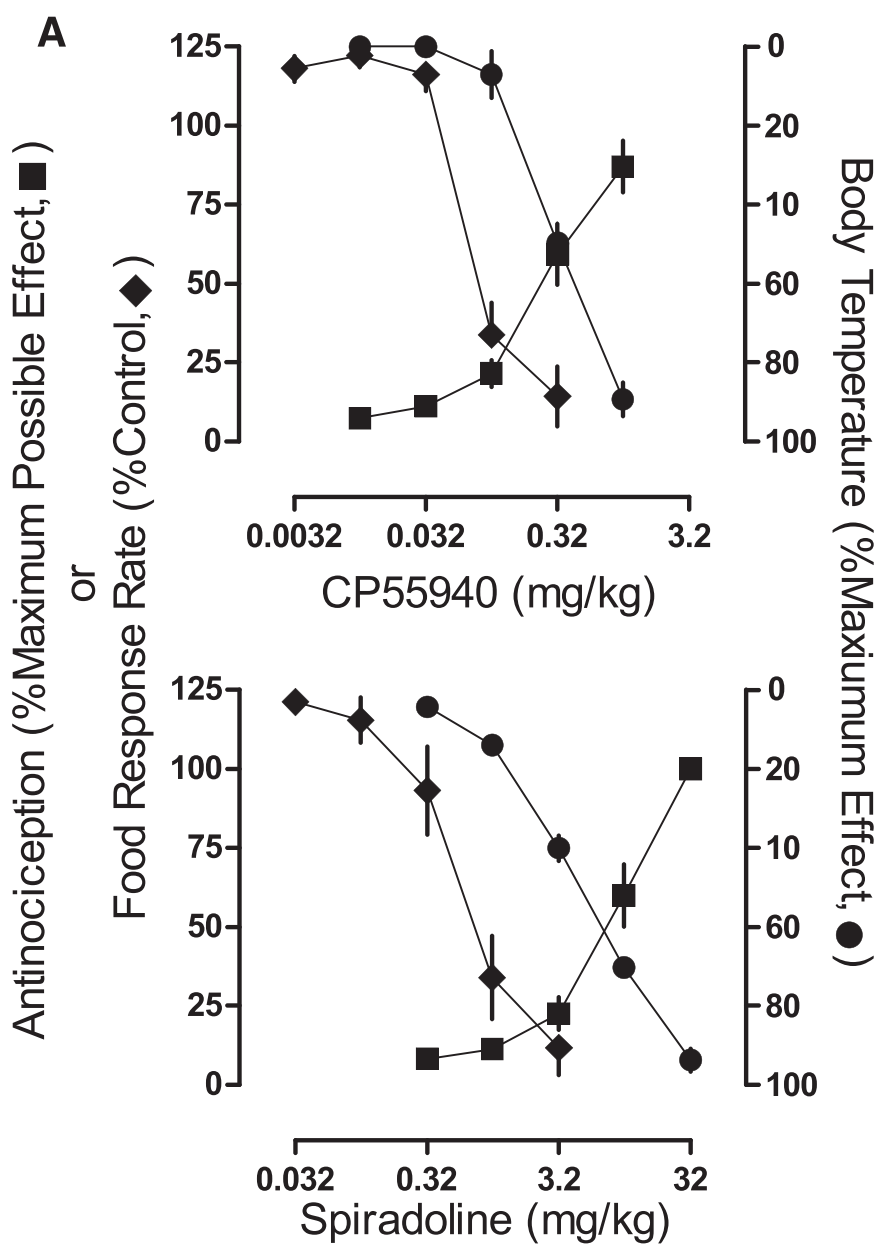

B

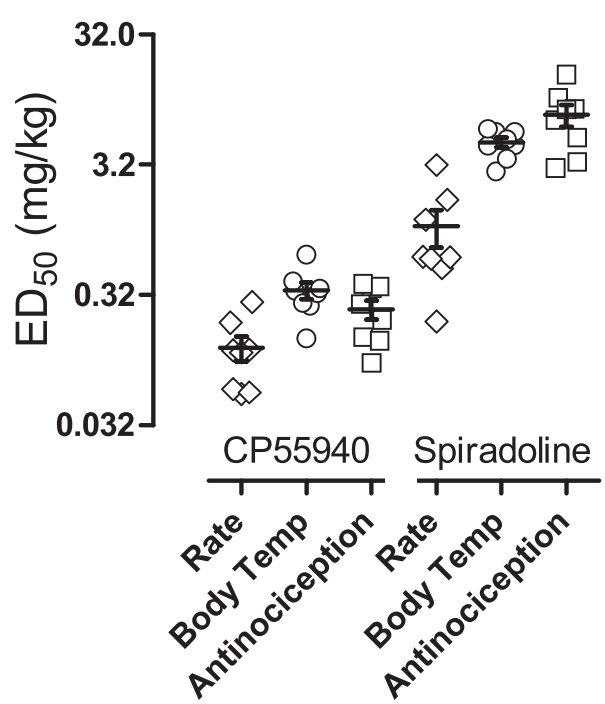

Fig. 1. (A) Effects of CP55940 (upper) and spiradoline (lower) alone on tail withdrawal latency from $50^{\circ} \mathrm{C}$ water (squares), responding for food (diamonds), and body temperature (circles) in eight rats. Abscissae: cumulative dose in $\mathrm{mg} / \mathrm{kg}$ body weight. Ordinate: percentage of maximum possible effect \pm 1 S.E.M. (B) Dot plot showing individual $\mathrm{ED}_{50}$ values for CP55940 and spiradoline alone for the data presented in (A), except that open symbols are used to avoid concealing the mean (horizontal lines) and error ( \pm 1 S.E.M.). Abscissae: assays (rate of responding for food, body temperature, and antinociception) for both drugs. Ordinate: $\mathrm{ED}_{50}$ values in $\mathrm{mg} / \mathrm{kg}$ body weight. 
responding was examined, as previously described (Tallarida, 2006, 2011). Based on the $\mathrm{ED}_{50}, \mathrm{E}_{\max }$, and slope of each drug (given alone), the dose of CP55940 in the mixture was converted to spiradoline equivalence for individual rats according to the following equation described by Grabovsky and Tallarida (2004):

$$
b e q(a)=\mathrm{ED}_{50} \mathrm{~A} /\left[\left(\mathrm{E}_{\max } \mathrm{A} / \mathrm{E}_{\max } \mathrm{B}\right)\left(1+\mathrm{ED}_{50} \mathrm{~B}^{q} / \mathrm{b}^{q}\right)-1\right]^{1 / P},
$$

where $\mathrm{ED}_{50} \mathrm{~A}$ and $\mathrm{ED}_{50} \mathrm{~B}$ are the doses of drugs $\mathrm{A}$ and $\mathrm{B}$ estimated to produce a $50 \%$ effect, $\mathrm{E}_{\max } \mathrm{A}$ and $\mathrm{E}_{\max } \mathrm{B}$ are the maximum effect levels for drugs $\mathrm{A}$ and $\mathrm{B}, a$ is dose of drug $\mathrm{A}$, and $q$ and $p$ are the slopes derived from the linear regression analyses of drugs $\mathrm{A}$ and $\mathrm{B}$, respectively. The total additive dose (CP55940 in spiradoline equivalence plus spiradoline) was calculated by adding $b e q(a)+a$, and that was used to determine predicted effects (additive interaction) for individual rats using the following equation described by Grabovsky and Tallarida (2004):

$$
\text { predicted effect level }=\left[\mathrm{E}_{\max } \mathrm{A}\left(\mathrm{eqA}^{p}\right)\right] /\left[\left(\mathrm{E}_{\max } \mathrm{A}\left[\mathrm{eqA}^{p}\right]\right)+\left(\mathrm{ED}_{50} \mathrm{~A}^{p}\right)\right]
$$

Next, a linear regression was fit to all data (i.e., from all rats, not averaged) between the largest dose that produced not more than $20 \%$ and the smallest dose that produced at least $80 \%$ of the predicted effects and the observed effects (empirically determined). No more than one dose producing less than $20 \%$ effect was included, and no more than one dose producing greater than $80 \%$ was included for individual rats to obtain the most accurate estimate of the slope of the linear portion of the doseresponse curve. The slopes and $y$-intercepts were compared using an $F$ test for each ratio. Urine data were analyzed with a one-way repeated measures analysis of variance and Bonferroni's post hoc test. $\mathrm{ED}_{50}$ values were analyzed with a two-way repeated measures analysis of variance (drug $\times$ assay) and Bonferroni's post hoc test for multiple comparisons. Analyses were conducted using GraphPad Prism (GraphPad Software, La Jolla, CA).

\section{Results}

There was no significant difference between the two control conditions (i.e., 1:1:18 vehicle and saline) for any of the assays. Mean ( \pm 1 S.E.M.) control tail withdrawal latencies from $50^{\circ} \mathrm{C}$ water were $3.1(0.3)$ seconds for the 1:1:18 vehicle (administered prior to CP55940) and 3.5 (0.2) seconds for saline (administered prior to spiradoline); mean control body temperatures were $37.4^{\circ} \mathrm{C}(0.1)$ for $1: 1: 18$ vehicle and $37.4^{\circ} \mathrm{C}(0.1)$ for saline. Control response rates were $0.86(0.05)$ and $0.82(0.05)$ responses per second for 1:1:18 vehicle and saline, respectively. Urine output was $1.39(0.08) \mathrm{g}$ for 1:1:18 vehicle and $1.42(0.07) \mathrm{g}$ for saline. Rates of responding were stable across six saline cycles, as follows: 0.87 (0.04), 0.87 (0.05), 0.94 (0.04), 0.94 (0.05), 0.89 (0.04), and 0.85 (0.06).

Cumulative doses of CP55940 alone and spiradoline alone increased tail withdrawal latencies from $50^{\circ} \mathrm{C}$ water to greater than $80 \%$ of the maximum possible effect, decreased responding for food to less than $20 \%$ of control response rates, and decreased body temperature to at least $80 \%$ of the maximum observed effect (Fig. 1A). Individual $\mathrm{ED}_{50}$ values for the two drugs are shown in Fig. 1B. The rank order potency of CP55940 across the three measures was response rate $>$ antinociception $>$ body temperature, and the rank order potency of spiradoline was response rate $>$ body temperature $>$ antinociception. Potency differences across assays were statistically significant for spiradoline $(t=8.36, P<0.0001$ for response rate versus antinociception; $t=3.34, P<0.05$ for body temperature versus response rate; $t=5.01, P<0.001$ for body temperature versus antinociception) but not for CP55940 $(t=1.07, P>0.05$ for response rate versus antinociception; $t=0.25, P>0.05$ for body temperature versus response rate; and $t=0.82, P>0.05$ for body temperature versus antinociception). At doses that markedly affected both responding for food (decreasing rates to less than $20 \%$ of control) and body temperature (decreasing temperature to at least $50 \%$ of the maximum observed effect), spiradoline $(3.2 \mathrm{mg} / \mathrm{kg})$, but not CP55940 $(0.32 \mathrm{mg} / \mathrm{kg})$, significantly increased urine output ( $t=4.54, P<0.0001$; Table 2$)$.

In mixtures, CP55940 enhanced the potency of spiradoline, and spiradoline enhanced the potency of CP55940. As the ratio of spiradoline:CP55940 in the mixture decreased, the doseeffect functions shifted to the left (see Supplemental Fig. 1). The nature of this interaction was determined using the quantitative methods of dose equivalence and dose additivity and is presented in Fig. 2. Mixtures of spiradoline and CP55940 increased tail withdrawal latency from $50^{\circ} \mathrm{C}$ water to at least $80 \%$ of the maximum possible effect (filled squares, Fig. 2A), decreased body temperature to at least $80 \%$ of the maximum observed effect (filled circles, Fig. 2B), and decreased responding for food to at least $20 \%$ of control rates (filled diamonds, Fig. 2C) in a dose-related manner.

For antinociception, the observed effects for all three ratios were not significantly different from the predicted effects (open squares, Fig. 2A; additive interaction, see Table 3 for statistical analyses of slopes and $y$-intercepts). For body temperature, the observed effects for all three ratios were significantly different from the predicted effects (open circles, Fig. 2B). For the 3:1 spiradoline/CP55940 mixture (Fig. 2B, left panel), the observed effects were greater than the predicted effects. The $y$-intercepts (Table $3 ;[F(1,67)=23.70, P<0.001]$ ), but not the slopes (Table $3 ;[F(1,66)=3.91, P=0.052]$ ), were significantly different, indicating a greater than additive interaction for the 3:1 mixture. For the 1:1 and 1:3 spiradoline/CP55940 mixtures (Fig. 2B, center and right panels), the slopes were significantly different for the observed effects (Table $3 ;[F(1,62)=20.14$, $P \leq 0.001$ for $1: 1$ and $F(1,63)=10.5, P=0.0019$ for $1: 3])$.

TABLE 2

Statistical analyses of the effects of saline and drug treatments on urine output, expressed as an absolute change (g) from control

The control was the mean urine output from three sessions preceding each treatment.

\begin{tabular}{lcccc}
\multicolumn{1}{c}{ Treatment } & Dose $(\mathrm{mg} / \mathrm{kg})$ & Urine $(\Delta$ Control, g) & S.E.M. & Post Hoc Test (Drug versus Saline) \\
\hline Saline & $\mathrm{n} / \mathrm{a}$ & -0.251 & 0.115 & $\mathrm{n} / \mathrm{a}$ \\
CP55940 & 0.32 & 1.185 & 0.348 & $t=1.02, \mathrm{n} . \mathrm{s}$. \\
Spiradoline & 3.2 & 6.127 & 0.211 & $t=4.54, * * * P<0.0001$ \\
3:1 Spiradoline:CP55940 & 3.3 Spiradoline + 0.13 CP55940 & 7.658 & 1.370 & $t=5.63, * * * P<0.0001$ \\
1:1 Spiradoline:CP55940 & 1.1 Spiradoline + 0.13 CP55940 & 4.362 & 1.512 & $t=3.29, * P<0.05$ \\
1:3 Spiradoline:CP55940 & 1.1 Spiradoline + 0.39 CP55940 & 6.813 & 0.994 & $t=5.03, * * * P<0.001$ \\
\hline
\end{tabular}

n.s., Not significant. 


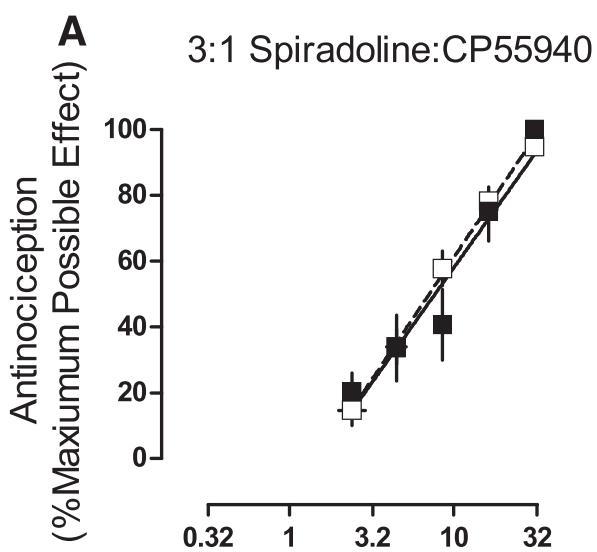

1:1 Spiradoline:CP55940

1:3 Spiradoline:CP55940
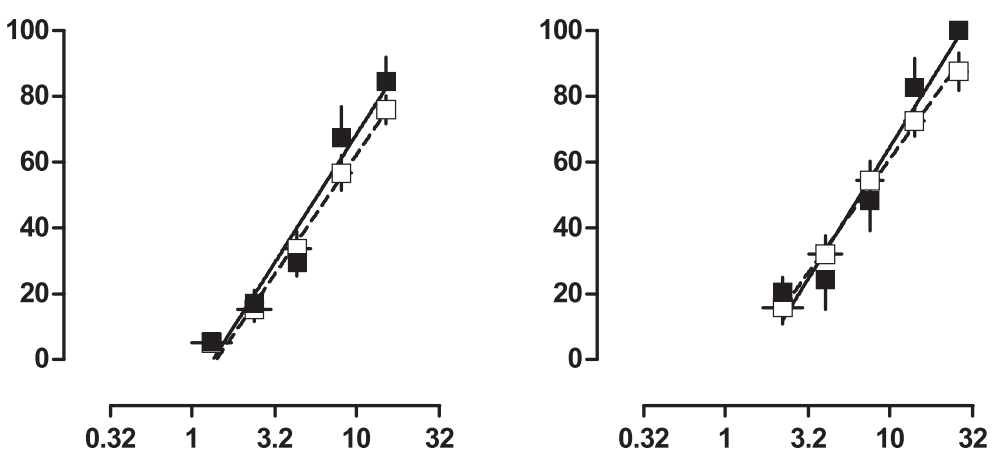

B
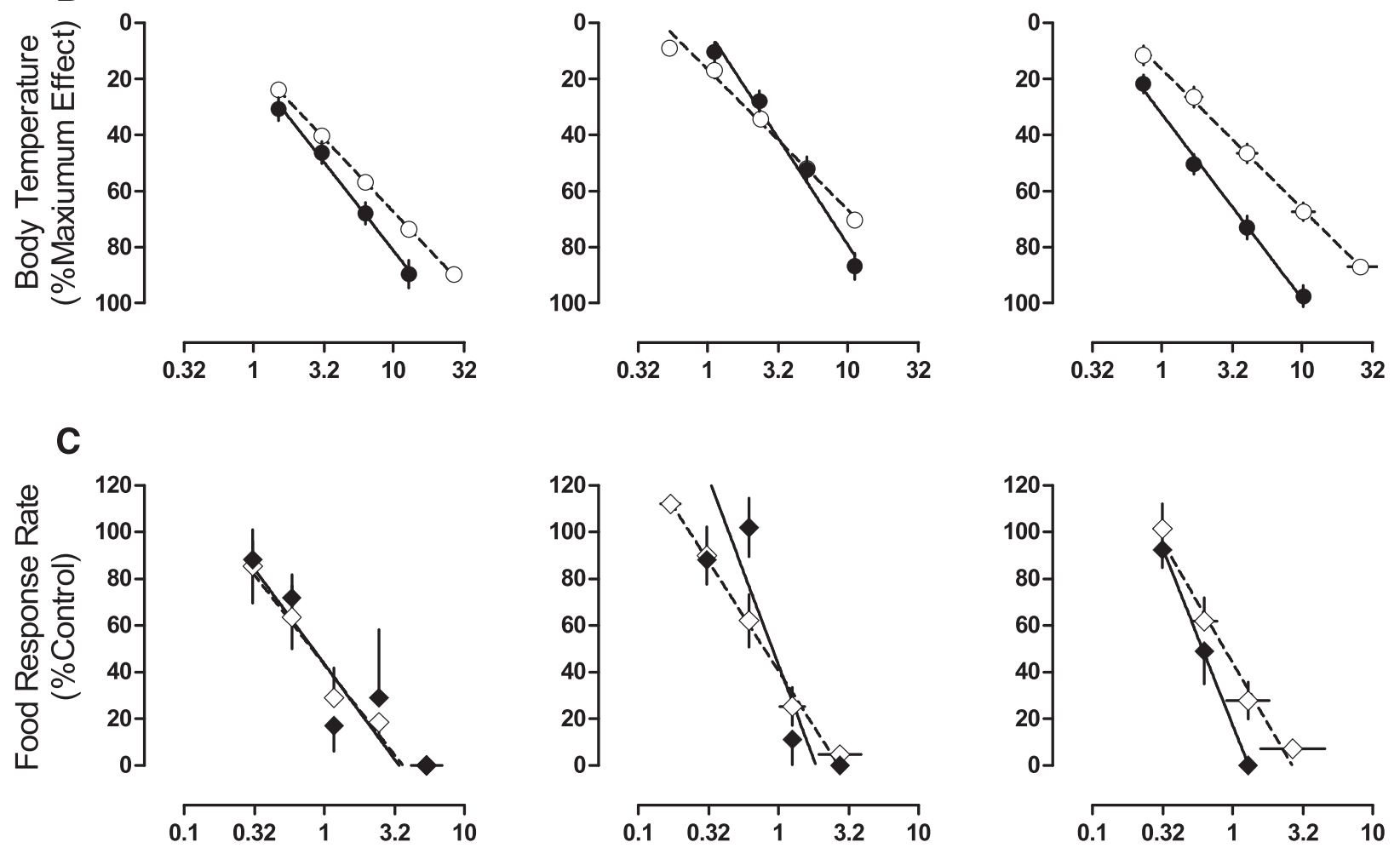

Spiradoline Equivalent Dose $(\mathrm{mg} / \mathrm{kg})$

Fig. 2. Predicted effects for an additive interaction (open symbols, dashed lines) and observed effects (filled symbols, solid lines) of the spiradoline: CP55940 mixtures for each dose ratio (columns) across three assays (rows) in eight rats. Abscissae: spiradoline equivalent dose (total additive dose; see Data Analyses for details) in the mixture ( \pm 1 S.E.M.). See Table 3 for statistical analyses. (A) Comparison of predicted and observed antinociceptive effects with $50^{\circ} \mathrm{C}$ water (squares). Ordinate: percentage of maximum possible effect ( \pm 1 S.E.M.). (B) Comparison of predicted and observed effects on body temperature (circles). Ordinate: percentage of maximum effect ( \pm 1 S.E.M.). (C) Comparison of predicted and observed effects on responding for food (diamonds). Ordinate: percentage of control response rate ( \pm 1 S.E.M.).

Although the y-intercepts could not be compared statistically, the observed effects for the 1:3 mixture were shifted to the left (approximately $1 / 2 \log$ unit smaller doses) of the predicted effects (Fig. 2B, right panel), and the $y$-intercept was twofold greater than the predicted effects (Table 3). Thus, the interaction for the 1:3 mixture appeared to be greater than additive.

For response rate, the observed effects for the $3: 1$ and 1:1 spiradoline/CP55940 mixtures (Fig. 2C, left and center panels) were not significantly different from the predicted effects (open diamonds, Fig. 2C; see Table 3 for statistical analyses of slopes and $y$-intercepts). For the 1:3 spiradoline/CP55940 mixture (Fig. 2C, right panel), the observed effects were shifted to the left of the predicted effects. The $y$-intercept (Table 3; $[F(1,41)=6.02, P=0.018]$ ), but not the slope (Table 3 ; $[F(1,40)=2.88, P=0.98])$, was significantly greater for the observed effects compared with the predicted effects, indicating a greater than additive interaction for the 1:3 mixture.

The effects of 3:1, 1:1, and 1:3 spiradoline/CP55940 mixtures on urine output are shown in Table 2. For all mixtures, urine output was increased significantly $(t=5.63, P<0.0001$ 
TABLE 3

Statistical analyses of the predicted (additive) versus observed (empirically determined) effects of spiradoline:CP55940 mixtures for antinociception, body temperature, and responding for food, as shown in Fig. 2

Note that $y$-intercepts are the values of $y$ when $\log (x)=0$.

\begin{tabular}{|c|c|c|c|c|c|}
\hline & & Predicted & Observed & $F$ Test & $P$ \\
\hline \multicolumn{6}{|l|}{ Antinociception } \\
\hline \multirow[t]{2}{*}{ 3:1 Spiradoline:CP55940 } & Slope & 74.76 & 70.22 & $F(1,66)=0.12$ & 0.733 \\
\hline & $y$-Intercept & -13.31 & -12.14 & $F(1,67)=0.32$ & 0.574 \\
\hline \multirow[t]{2}{*}{ 1:1 Spiradoline:CP55940 } & Slope & 73.18 & 78.44 & $F(1,66)=0.25$ & 0.620 \\
\hline & $y$-Intercept & -11.04 & -10.09 & $F(1,67)=1.60$ & 0.210 \\
\hline \multirow[t]{2}{*}{ 1:3 Spiradoline:CP55940 } & Slope & 69.59 & 80.72 & $F(1,65)=0.76$ & 0.388 \\
\hline & $y$-Intercept & -8.75 & -16.27 & $F(1,66)=0.16$ & 0.695 \\
\hline \multicolumn{6}{|l|}{ Body temperature } \\
\hline \multirow[t]{2}{*}{ 3:1 Spiradoline:CP55940 } & Slope & 52.98 & 63.80 & $F(1,66)=3.91$ & 0.052 \\
\hline & $y$-Intercept & 14.48 & 17.51 & $F(1,67)=23.70$ & $* * *<0.001$ \\
\hline \multirow[t]{2}{*}{ 1:1 Spiradoline:CP55940 } & Slope & 50.14 & 76.63 & $F(1,62)=20.14$ & $* * *<0.001$ \\
\hline & $y$-Intercept & 16.55 & 2.52 & $\mathrm{n} / \mathrm{a}$ & $\mathrm{n} / \mathrm{a}$ \\
\hline \multirow[t]{2}{*}{ 1:3 Spiradoline:CP55940 } & Slope & 49.68 & 65.97 & $F(1,63)=10.50$ & $* * 0.0019$ \\
\hline & $y$-Intercept & 16.57 & 32.47 & $\mathrm{n} / \mathrm{a}$ & $\mathrm{n} / \mathrm{a}$ \\
\hline \multicolumn{6}{|l|}{ Response rate } \\
\hline \multirow[t]{2}{*}{ 3:1 Spiradoline:CP55940 } & Slope & -77.12 & -81.45 & $F(1,42)=0.02$ & 0.881 \\
\hline & $y$-Intercept & 43.34 & 43.67 & $F(1,43)=0.01$ & 0.946 \\
\hline \multirow[t]{2}{*}{ 1:1 Spiradoline:CP55940 } & Slope & -93.95 & -160.20 & $F(1,39)=3.52$ & 0.068 \\
\hline & $y$-Intercept & 40.65 & 43.30 & $F(1,40)=0.64$ & 0.427 \\
\hline \multirow[t]{2}{*}{ 1:3 Spiradoline:CP55940 } & Slope & -103.40 & -151.60 & $F(1,40)=2.88$ & 0.098 \\
\hline & $y$-Intercept & 44.15 & 17.54 & $F(1,41)=6.02$ & $* 0.018$ \\
\hline
\end{tabular}

for $3: 1 ; t=3.29, P<0.05$ for $1: 1 ; t=5.03, P<0.001$ ) compared with saline, although these increases were not significantly different from the effect of spiradoline alone.

\section{Discussion}

Pain remains a significant clinical problem (Gaskin and Richard, 2012), and $\mu$ opioid receptor agonists remain the drugs of choice for treating moderate to severe pain, despite the high abuse liability of these drugs and a current epidemic of fatal drug overdoses (Wightman et al., 2012; Volkow et al., 2014). Consequently, there is a pressing need to identify alternative pharmacotherapies with reduced adverse effects that currently limit the clinical use of $\mu$ opioid receptor agonists. Previous work showed that mixtures comprising small doses of the $\kappa$ opioid receptor agonist spiradoline and the cannabinoid receptor agonist CP55940 had antinociceptive effects that were equivalent to the effects of larger doses of either drug given alone (Maguire and France, 2016). In that study, dose-additivity analyses revealed an additive interaction for antinociception, suggesting that spiradoline/CP55940 mixtures might be useful for treating pain, but only if adverse effects of mixtures were less than additive. The purpose of the present experiment was to examine the therapeutic potential of spiradoline/CP55940 mixtures by characterizing effects on antinociception, body temperature, urine output, and food-maintained responding. The hypothesis was that smaller doses in mixtures have antinociceptive effects in the absence of adverse effects.

CP55940 alone and spiradoline alone dose dependently increased tail withdrawal latency (antinociception), decreased body temperature (hypothermia), and decreased responding for food, and these results were consistent with previous studies (Leander, 1983; Brandt and France, 1996; Mello and Negus, 1998; Smith et al., 2003; Terner et al., 2003; De Vry and Jentzsch, 2004; Craft et al., 2012; Deng et al., 2015). Hypothermic effects have been reported for the $\kappa$ opioid receptor agonists U50488, U69593, and salvinorin A (Hayes et al., 1985;
Cavicchini et al., 1989; Nemmani et al., 2001; Baker and Meert, 2002), and there is a report of spiradoline producing hypothermia after intracerebroventricular administration (Adler and Geller, 1993). The present study generated full dose-response functions for the hypothermic effects of spiradoline after i.p. administration. Cannabinoid receptor agonists have well-documented diuretic effects (Paronis et al., 2013); up to doses affecting foodmaintained responding, spiradoline alone, but not CP55940 alone, significantly increased urine output. Despite the lack of statistical significance, CP55940 $(0.32 \mathrm{mg} / \mathrm{kg})$ modestly increased urine output (1.2 $\mathrm{g}$ above control levels); however, there was considerable variability among subjects with marked diuretic effects in some, but not all rats. Urine output was assessed in operant sessions when $0.32 \mathrm{mg} / \mathrm{kg}$ CP55940 was the largest cumulative dose tested; it is possible that larger doses of CP55940 significantly increase urine output in all rats.

$\mathrm{ED}_{50}$ values for each drug administered alone were used to determine the doses for CP55940/spiradoline mixtures in ratios of $3: 1,1: 1$, and 1:3. CP55940 and spiradoline have similar onsets and durations of action when administered i.p., with onset occurring within 30 minutes and offset occurring within 3 hours (Briggs et al., 1998; Tseng and Craft, 2001; Barrett et al., 2002; Hamamoto et al., 2007; Chang et al., 2011); this similarity in time course was the basis for using cumulative dosing for drugs alone and in mixtures. Mixtures comprising smaller doses of CP55940 and spiradoline had effects that were equivalent to or greater than the effects observed with larger doses of either drug administered alone. For example, the $\mathrm{ED}_{50}$ values of each drug alone $(7.74 \mathrm{mg} / \mathrm{kg}$ spiradoline and $0.25 \mathrm{mg} / \mathrm{kg}$ CP55940) were the largest cumulative doses administered of the 1:1 spiradoline/CP55940 mixture and produced at least $80 \%$ of the maximum possible effect for antinociception, consistent with a previous study (Maguire and France, 2016). Similarly, when $1.1 \mathrm{mg} / \mathrm{kg}$ spiradoline and $0.13 \mathrm{mg} / \mathrm{kg}$ CP55940 (ED ${ }_{50}$ values for decreasing food-maintained responding) were administered as the largest cumulative dose of the 1:1 mixture, responding for food was nearly eliminated. 
Interactions for the mixtures across assays were examined quantitatively using dose-additivity analyses (Tallarida, 2006, 2011). The nature of the interaction between spiradoline and CP55940 was additive for antinociceptive effects with all mixtures; in contrast, interactions were greater than additive with some mixtures for hypothermia (3:1 and 1:3) and foodmaintained responding (1:3). The slopes of the observed effects were steeper than the slopes of the predicted effects in two conditions (hypothermia, 1:1 and 1:3 mixtures), indicating that the nature of the interaction varied depending on dose; the interaction was additive or less than additive for small doses of mixtures and greater than additive for larger doses of mixtures. Thus, at doses of mixtures producing antinociception, the interaction for hypothermia was either additive (1:1) or greater than additive (1:3).

Dose-additivity analyses were not conducted for diuresis because total urine output was measured only at the end of the session (i.e., dose-response curves were not determined); however, it was evident that all three spiradoline/CP55940 mixtures increased urine output to levels that were comparable to $3.2 \mathrm{mg} / \mathrm{kg}$ spiradoline administered alone. There was more variability in urine output among rats with the mixtures compared with saline or either drug administered alone. Thus, at least for some rats and some mixtures, the magnitude of the diuretic effect of spiradoline was diminished by the addition of a dose of CP55940 that was without effect alone. Although diuresis can be a desired effect under some conditions, frequent and high volume urination might pose a significant impediment during the treatment of pain, particularly in patients with restricted mobility or other medical complications.

In summary, the primary findings of this study are that interactions between CP55940 and spiradoline were additive for antinociception and were additive or greater than additive (synergistic) for hypothermia and food-maintained responding. Additionally, doses that eliminated responding for food and increased urine output were without antinociceptive effects. Collectively, these findings fail to provide support for the notion that an acceptable therapeutic window (i.e., for treating pain) can be established for a $\kappa$ opioid receptor agonist by combining it with a cannabinoid receptor agonist because other effects of spiradoline were also enhanced by CP55940. Significant adverse effects of $\kappa$ opioids that preclude their use in the clinic include hallucinations and dysphoria (Pfeiffer et al., 1986), and it is unknown whether cannabinoids enhance those effects in humans. Although cannabinoids are widely abused (Wang et al., 2008; Pertwee, 2009; Rahn and Hohmann, 2009), they can also produce aversive effects (McGregor et al., 1996; Tzschentke, 2007). $\Delta^{9}$-Tetrahydrocannabinol-induced conditioned place avoidance is diminished in knockout mice lacking either $\kappa$ opioid receptors or the endogenous $\kappa$ opioid peptide dynorphin (Zimmer et al., 2001; Ghozland et al., 2002), suggesting an interaction between cannabinoid receptor agonists and $\kappa$ opioid receptor agonists for aversive effects. In rats, the aversive effects, but not the antinociceptive effects, of $\kappa$ opioid receptor agonists are attenuated during a state of chronic inflammatory pain (Shippenberg and Herz, 1987; Shippenberg et al., 1988), raising the possibility that those $\kappa$ opioid/cannabinoid mixtures might interact differently under chronic pain conditions, compared with the acute pain model used in the current study. Thus, mixtures of $\kappa$ opioids and cannabinoids might have therapeutic potential for treating chronic pain or other types of pain (not caused by a thermal stimulus), but only if adverse effects can be avoided and an acceptable therapeutic window can be established.

\section{Acknowledgments}

We thank Lisa Gerak for helpful comments on the data set and previous drafts of this manuscript.

\section{Authorship Contributions}

Participated in research design: Minervini, France.

Conducted experiments: Minervini, Dahal.

Performed data analysis: Minervini, Dahal.

Wrote or contributed to the writing of the manuscript: Minervini, France.

\section{References}

Adler MW and Geller EB (1993) Physiological function of opioid: temperature regulation, in Opioids II (Herz A ed) pp 205-229, Springer-Verlag, Berlin.

Baker AK and Meert TF (2002) Functional effects of systemically administered agonists and antagonists of $\mathrm{mu}, \delta$, and kappa opioid receptor subtypes on body temperature in mice. J Pharmacol Exp Ther 302:1253-1264.

Barrett AC, Cook CD, Terner JM, Roach EL, Syvanthong C, and Picker MJ (2002) Sex and rat strain determine sensitivity to kappa opioid-induced antinociception. Psychopharmacology (Berl) 160:170-181.

Binder W, Machelska H, Mousa S, Schmitt T, Rivière PJM, Junien JL, Stein C, and Schäfer M (2001) Analgesic and antiinflammatory effects of two novel kappaopioid peptides. Anesthesiology 94:1034-1044.

Brandt MR and France CP (1996) Discriminative stimulus effects on enadoline in pigeons. J Pharmacol Exp Ther 277:960-967.

Briggs SL, Rech RH, and Sawyer DC (1998) Kappa antinociceptive activity of spiradoline in the cold-water tail-flick assay in rats. Pharmacol Biochem Behav 60: $467-472$.

Cavicchini E, Candeletti S, Spampinato S, and Ferri S (1989) Hypothermia elicited by some prodynorphin-derived peptides: opioid and non-opioid actions. Neuropeptides 14:45-50.

Chang C, Byon W, Lu Y, Jacobsen LK, Badura LL, Sawant-Basak A, Miller E, Liu J, Grimwood S, Wang EQ, et al. (2011) Quantitative PK-PD model-based translational pharmacology of a novel kappa opioid receptor antagonist between rats and humans. AAPS $J$ 13:565-575.

Chavkin C (2011) The therapeutic potential of $\kappa$-opioids for treatment of pain and addiction. Neuropsychopharmacology 36:369-370.

Chopda GR, Vemuri VK, Sharma R, Thakur GA, Makriyannis A, and Paronis CA (2013) Diuretic effects of cannabinoid agonists in mice. Eur J Pharmacol 721: 64-69.

Craft RM, Wakley AA, Tsutsui KT, and Laggart JD (2012) Sex differences in cannabinoid 1 vs. cannabinoid 2 receptor-selective antagonism of antinociception produced by delta9-tetrahydrocannabinol and CP55,940 in the rat. J Pharmacol Exp Ther 340:787-800.

De Vry J and Jentzsch KR (2004) Partial agonist-like profile of the cannabinoid receptor antagonist SR141716A in a food-reinforced operant paradigm. Behav Pharmacol 15:13-20.

Deng L, Cornett BL, Mackie K, and Hohmann AG (2015) CB1 knockout mice unveil sustained CB2-mediated antiallodynic effects of the mixed CB1/CB2 agonist CP55,940 in a mouse model of paclitaxel-induced neuropathic pain. Mol Pharmacol 88:64-74.

Desmeules JA, Kayser V, and Guilbaud G (1993) Selective opioid receptor agonists modulate mechanical allodynia in an animal model of neuropathic pain. Pain 53: $277-285$.

Dykstra LA, Gmerek DE, Winger G, and Woods JH (1987) Kappa opioids in rhesus monkeys. I. Diuresis, sedation, analgesia and discriminative stimulus effects. $J$ Pharmacol Exp Ther 242:413-420.

Gaskin DJ and Richard P (2012) The economic cost of pain in the United States. $J$ Pain 13: 715-724.

Gerak LR and France CP (2016) Combined treatment with morphine and $\Delta 9$-tetrahydrocannabinol in rhesus monkeys: antinociceptive tolerance and withdrawal. $J$ Pharmacol Exp Ther 357:357-366.

Ghozland S, Matthes HW, Simonin F, Filliol D, Kieffer BL, and Maldonado R (2002) Motivational effects of cannabinoids are mediated by mu-opioid and kappa-opioid receptors. J Neurosci 22:1146-1154.

Grabovsky Y and Tallarida RJ (2004) Isobolographic analysis for combinations of a full and partial agonist: curved isoboles. J Pharmacol Exp Ther 310:981-986.

Hamamoto DT, Giridharagopalan S, and Simone DA (2007) Acute and chronic administration of the cannabinoid receptor agonist CP 55,940 attenuates tumorevoked hyperalgesia. Eur J Pharmacol 558:73-87.

Hayes AG, Skingle M, and Tyers MB (1985) Effect of beta-funaltrexamine on opioid side-effects produced by morphine and U-50, 488H. J Pharm Pharmacol 37: 841-843.

Kivell B and Prisinzano TE (2010) Kappa opioids and the modulation of pain. Psychopharmacology 210:109-119.

Lalanne L, Ayranci G, Kieffer BL, and Lutz PE (2014) The kappa opioid receptor: from addiction to depression, and back. Front Psychiatry 5:170.

Leander JD (1983) Further study of kappa opioids on increased urination. J Pharmacol Exp Ther 227:35-41.

Maguire DR and France CP (2016) Additive antinociceptive effects of mixtures of the $\kappa$-opioid receptor agonist spiradoline and the cannabinoid receptor agonist CP55940 in rats. Behav Pharmacol 27:69-72. 
Maguire DR, Yang W, and France CP (2013) Interactions between $\mu$-opioid receptor agonists and cannabinoid receptor agonists in rhesus monkeys: antinociception, drug discrimination, and drug self-administration. J Pharmacol Exp Ther $\mathbf{3 4 5}$ 354-362.

McGregor IS, Issakidis CN, and Prior G (1996) Aversive effects of the synthetic cannabinoid CP 55,940 in rats. Pharmacol Biochem Behav 53:657-664.

Mellow NK and Negus SS (1998) Effects of kappa opioid agonists on cocaine- and food-maintained responding by rhesus monkeys. J Pharmacol Exp Ther 286: $812-824$.

Nemmani KV, Gullapalli S, and Ramarao P (2001) Potentiation of kappa-opioid receptor agonist-induced analgesia and hypothermia by fluoxetine. Pharmacol Biochem Behav 69:189-193.

Paronis CA, Nikas SP, Shukla VG, and Makriyannis A (2012) $\Delta(9)$-Tetrahydrocannabinol acts as a partial agonist/antagonist in mice. Behav Pharmacol 23:802-805.

Paronis CA, Thakur GA, Bajaj S, Nikas SP, Vemuri VK, Makriyannis A, and Bergman $J$ (2013) Diuretic effects of cannabinoids. J Pharmacol Exp Ther 344:8-14.

Pertwee RG (2009) Emerging strategies for exploiting cannabinoid receptor agonists as medicines. Br J Pharmacol 156:397-411.

Peters GR, Ward NJ, Antal EG, Lai PY, and deMaar EW (1987) Diuretic actions in man of a selective kappa opioid agonist: U-62,066E. J Pharmacol Exp Ther 240: 128-131.

Pfeiffer A, Brantl V, Herz A, and Emrich HM (1986) Psychotomimesis mediated by kappa opiate receptors. Science 233:774-776.

Pugh G, Jr, Mason DJ, Jr, Combs V, and Welch SP (1997) Involvement of dynorphin B in the antinociceptive effects of the cannabinoid CP55,940 in the spinal cord. $J$ Pharmacol Exp Ther 281:730-737.

Pugh G, Jr, Smith PB, Dombrowski DS, and Welch SP (1996) The role of endogenous opioids in enhancing the antinociception produced by the combination of delta 9-tetrahydrocannabinol and morphine in the spinal cord. J Pharmacol Exp Ther 279:608-616.

Rahn EJ and Hohmann AG (2009) Cannabinoids as pharmacotherapies for neuropathic pain: from the bench to the bedside. Neurotherapeutics 6:713-737.

Rawls SM and Benamar K (2011) Effects of opioids, cannabinoids, and vanilloids on body temperature. Fron Biosci 3:822-845

Rosenblatt RA and Catlin M (2012) Opioids for chronic pain: first do no harm. Ann Fam Med 10:300-301.

Shippenberg TS and Herz A (1987) Place preference conditioning reveals the involvement of D1-dopamine receptors in the motivational properties of mu- and kappa-opioid agonists. Brain Res 436:169-172.

Shippenberg TS, Stein C, Huber A, Millan MJ, and Herz A (1988) Motivational effects of opioids in an animal model of prolonged inflammatory pain: alteration in the effects of kappa- but not of mu-receptor agonists. Pain 35:179-186.

Smith MA, Bryant PA, and McClean JM (2003) Social and environmental enrichment enhances sensitivity to the effects of kappa opioids: studies on antinociception, diuresis and conditioned place preference. Pharmacol Biochem Behav 76:93-101.

Smith MA, Cole KT, Gergans SR, Iordanou JC, Lyle MA, and Schmidt KT (2008) Effects of environmental enrichment on sensitivity to mu, kappa, and mixed-action opioids in female rats. Physiol Behav 94:563-568.
Smith PB, Welch SP, and Martin BR (1994) Interactions between delta 9-tetrahydrocannabinol and kappa opioids in mice. J Pharmacol Exp Ther 268: 1381-1387.

St Sauver JL, Warner DO, Yawn BP, Jacobson DJ, McGree ME, Pankratz JJ, Melton LJ, 3rd, Roger VL, Ebbert JO, and Rocca WA (2013) Why patients visit their doctors: assessing the most prevalent conditions in a defined American population. Mayo Clin Proc 88:56-67.

Tallarida RJ (2006) An overview of drug combination analysis with isobolograms. $J$ Pharmacol Exp Ther 319:1-7.

Tallarida RJ (2011) Quantitative methods for assessing drug synergism. Genes Cancer 2:1003-1008.

Tejeda HA, Counotte DS, Oh E, Ramamoorthy S, Schultz-Kuszak KN, Bäckman CM Chefer V, O’Donnell P, and Shippenberg TS (2013) Prefrontal cortical kappa-opioid receptor modulation of local neurotransmission and conditioned place aversion. Neuropsychopharmacology 38:1770-1779.

Terner JM, Barrett AC, Cook CD, and Picker MJ (2003) Sex differences in (-)-pentazocine antinociception: comparison to morphine and spiradoline in four rat strains using a thermal nociceptive assay. Behav Pharmacol 14:77-85.

Tseng AH and Craft RM (2001) Sex differences in antinociceptive and motoric effects of cannabinoids. Eur J Pharmacol 430:41-47.

Tzschentke TM (2007) Measuring reward with the conditioned place preference (CPP) paradigm: update of the last decade. Addict Biol 12:227-462.

Volkow ND, Frieden TR, Hyde PS, and Cha SS (2014) Medication-assisted therapies: tackling the opioid-overdose epidemic. N Engl J Med 370:2063-2066.

Wadenberg ML (2003) A review of the properties of spiradoline: a potent and selective kappa-opioid receptor agonist. CNS Drug Rev 9:187-198.

Walsh SL, Strain EC, Abreu ME, and Bigelow GE (2001) Enadoline, a selective kappa opioid agonist: comparison with butorphanol and hydromorphone in humans. Psychopharmacology 157:151-162.

Wang T, Collet JP, Shapiro S, and Ware MA (2008) Adverse effects of medical cannabinoids: a systematic review. CMAJ 178:1669-1678.

Wightman R, Perrone J, Portelli I, and Nelson L (2012) Likeability and abuse liability of commonly prescribed opioids. J Med Toxicol 8:335-340.

Woods JH and Winger G (1987) Behavioral characterization of opioid mixed agonistantagonists. Drug Alcohol Depend 20:303-315.

Zhang Y, Butelman ER, Schlussman SD, Ho A, and Kreek MJ (2005) Effects of the plant-derived hallucinogen salvinorin A on basal dopamine levels in the caudate putamen and in a conditioned place aversion assay in mice: agonist actions at kappa opioid receptors. Psychopharmacology 179:551-558.

Zimmer A, Valjent E, Konig M, Zimmer AM, Robledo P, Hahn H, Valverde O, and Maldonado R (2001) Absence of delta -9-tetrahydrocannabinol dysphoric effects in dynorphin-deficient mice. $J$ Neurosci 21:9499-9505.

Address correspondence to: Charles P. France, Department of Pharmacology, University of Texas Health Science Center, 7703 Floyd Curl Drive (Mail Code 7764), San Antonio, TX 78229-3900. E-mail: france@uthsca.edu 